\title{
Promotion of the Motoric Activities and Sports in and Out of School
}

\author{
Ardian Shingjergji \\ Elbasan University "Aleksandër Xhuvani", Faculty of Education Sciences. \\ ardianshingjergjigmail.com
}

Doi:10.5901/jesr.2014.v4n4p348

\begin{abstract}
Motions as well as the motoric and sportive activities constitute the key of success for a physically and psychologically healthy society. The reasons behind this study consist in addressing the children's need to move and deal with various motoric and sportive activities, on one hand, and the issues related to their sedentary life, standing in front of the TV and/or computer for hours on end, unhealthy nurturing, the lack of the proper infrastructure for sports activities, underestimation of the physical culture classes by the teachers, school directors and by other institutions of the state, on the other. In these terms, the aim of this study is promotion of the motoric and sportive activities in schools, not only during the physical education classes but even in the free and leisure time, by offering a suitable model for our conditions while compared to that of the developed European countries suchlike the "school on the move" programme. Subjects of the study are the 4-5 grades students and teachers in the Elbasan Town 9-year schools. The prevailing study methods are research, observation and sampling. Results drawn from this study have become object of discussion among school communities, teachers of physical education as well as the students of the respective profile at the Faculty of the Education Sciences, Elbasan University "Aleksander Xhuvani".
\end{abstract}

Keywords: promotion, school, motion, motoric activity, sports, modeling.

\section{Introduction}

Physical culture is an important component of the general culture of a country or nation, with its values reflected in its social and state institutions as well as into the systems of the physical education which are already well-known in the history of human society.

In its everyday use, the concept 'physical education' has been perceived in different ways so that its practical understanding is not very clear. Consequently, in present-day terminology one might encounter such terms as; motoric education, psychomotor education, sportive education, sports, etc.

Human activities are closely linked with motoric activities and sports and being such they have been considered of great interest by the physical education scholars and specialists. This interest has foremostly been seen in terms of mutual relationships between the physical education and sports as well as in other fields of physical education and social development.

The continuous improvement of the physical education subject educative, formative and integrative values have been perceived as requirements and challenges of drafting curricula and making it suitable for different student cycles and age-groups.

The school years, especially those of the 9-year school, are distinguished for the high intensity of students' relationships with the motoric and sportive experiences. Their interest and participation in curricula of different grade of difficulties have been motivated by some trends suchlike: physical, esthetical, psychological entertaining, social ones, etc.

Therefore, our education institutions it is required to consider the strong need for sportive and motor activities. To meet these needs and to promote the development of the students sportive and motoric needs, they should widely use the open activities of games, offering students possibilities to play in groups, to run, jump, crawl, etc. The numerous studies to this field show that the greatest physical body changes in children occur from 3-12 years of age and they are demonstrated via the desire to run, jump, and clamber in natural ambiances. (Kosanke, N., Warner, N., 1990). Such movements effect both to strengthen muscles and to support the growing of the cardiovascular and respiratory capacities as well as those other vital organs for the normal growth of children.

Actually, a general trend is being noticed nowadays: the time children spend with motoric or sportive activities is being ever and ever limited to the favor of the games into limited spaces or within their house, mainly the electronic games or TV.

Statistics show that most children in western developed countries (94\%), prefer spending more time out of the house rather than within it whereas $86 \%$ of their parents ascertain that children would like to play outside rather than watching TV. (Worpole, 2003 ). The situation is being repeated in a similar way in our country, Albania, as result of the 
economic and social changes that have been occurring, therefore, children prefer to play outside and deal with motoric and sportive activities, but their desires come diminishing because of the lack or limitations of the free and suitable ambiances or sportive playgrounds. This lack of access has made children to increase the time spent on computer or TV, bringing up, as a consequence, undesirable effects into their physical development and modifying their psycho-social development. (Craig A. Anderson, Karen E. Dill, 2002). It is enough to be simply mentioned, regarding the undesired consequences of child psychomotor development that simple exercises of force, (suchlike raising up the body in parallels solely by strength of arms, getting the body up and down off the floor solely by means of arms strength, creeping, jumping, etc), which the greatest part of the children of this generation find them very difficult, were very easy for the previous generation of children.

Another aspect showing the undisputable need for the promotion of the physical and sport activities in our schools is the malnutrition of this generation of children. Cases when children are being fed "by pleading and urging them to eat", or eat the same junk unhealthy food for days on end. Changes in the children's social economic conditions, and in terms of energy consumption, as result of not being activated in up-mentioned activities, have allowed for negative effects in increasing the obesity for these age-groups, (Viner, R.M., Cole, T.J., 2005), phenomena which were not known for the past generation children.

It is well-known now that the world of children is integrated in three big systems such as: family, school, and free time. These three systems are closely linked and impact each-other reciprocally. Parents participate in the school life, supporting it for its needs for motoric activities and sports whereas schools collaborate with local authorities for achieving their targets.

In this writing we are focusing at the role of the school into promoting the motoric and sportive activities which it fulfills by developing the physical culture curricula, determining the physical activities in and out of its territory. But this is not all; by promoting the "moving school" model, we are intending to extend this promotion even out of the school territory, by giving shape to a real physical culture whose effects would undoubtedly be beneficial for the society as a whole. This is a model which intertwines the common points between school and free time, out of which the following could be mentioned.

- School activities, school sports and optional activities.

- $\quad$ Teaching physical education in the classroom, and the sub-disciplinary teaching

- Motoric activities before and after school.

School activities containing excursions, expeditions, sport days, offer a suitable environment for movements and for an active and interesting life for students, away from the daily routines. In order to incite school or optional sport, the school ambiances can be used to organize students into sportive squads.

Lessons on physical education, as an important element of the school curricula and which is directed by wellprepared and specialist teachers, contributes into the harmonic development of the competent physical performance, socializes and integrates different students groups. Motion and sports are also very useful means for a universal teaching process which integrates cognition and wonts in different disciplines of the schools curricula. Moreover, the motoric activities before and after school is linked with the students home-school commuting and vice-versa, which is ideal to practice these activities. However, nowadays, students walking to school is diminishing, students are rarely going to school on foot or by bicycle which are the only ways to promote motion.

\section{Procedure of Application and Methods}

About 300 students of the 4-5 grades from different 9-year schools of the town were involved in this study, in addition to 20 low-cycle teachers as well as students of the Physical Education and Sports Department at the Faculty of the Education Sciences at the Elbasan University, "A. Xhuvani" Elbasan.

In order to effectively survey and reflect the factual reality, regarding the evolvement of this subject both in the teaching/learning process and out of it, we have been relying both on the home and foreign information, knowledge and literature, making use of the direct observations and contacts with the involved subjects as well as the data from the canvassing by means of the questionnaires realized for this very intention.

The students' age groups involved in the study varied from $10-12$ years of age, (the male/female rapport was $52 \% / 48 \%$ respectively), and they were also respondents to our selected questions, providing a clear tableau of the situation relevant to the study objectives.

The following were some of the questions formulated in the questionnaires for the involved students:

- Do you find dealing with physical activities and sports important and do you like the physical education classes? 
- $\quad$ Are the physical education classes developed regularly and do you like the way teachers organize it?

- Do you want to have more of the physical education and sports classes both at school and out of it, in your free time?

- Are you aware of the effective ways of organizing physical education and sports classes, the ways of healthy nutrition, etc?

- Have you ever been trained for games and sports in nature and do you have suitable ambiances to develop them?

- Do you like motor activities during breaks, the teaching/learning process developed at school and would you like that motor exercises evolved during the physical education classes to be integrated in other classes of mathematics, language, geography, history, etc?

In addition, the following are questions addressed to teachers:

- $\quad$ Are the physical education and sports classes developed in accordance to the selected curricula?

- Do you leave students to exert movements during the lessons' breaks at school?

- Do you have any knowledge for the "School in movement" model and how do you find the idea of its application?

- Do you support the integrated learning model, intertwining physical education with other subjects of school curricula?

- Do you ever give opinions or suggestions regarding the improvement of the methodical-pedagogical activity for the physical education and sports classes in and out of school?

\section{Results and Discussions}

The involved students and teachers' canvassing results have been presented on the summary table No. 1, with the respective Graphs No. 1, 2 and Graph No. 3.

Tab.1 Results (in \%) of the students' responses

\begin{tabular}{|c|c|c|c|c|c|}
\hline \multicolumn{3}{|c|}{ Grade IV } & \multicolumn{3}{c|}{ Grade IV } \\
\hline Nr of questions & Yes (\%) & No (\%) & Nr of questions & Yes(\%) & No (\%) \\
\hline 1 & 98.4 & 1.6 & 1 & 99.8 & 0.2 \\
\hline 2 & 28 & 72 & 2 & 52 & 48 \\
\hline 3 & 81 & 19 & 3 & 87 & 13 \\
\hline 4 & 45 & 55 & 4 & 47 & 53 \\
\hline 5 & 26 & 74 & 5 & 24 & 76 \\
\hline 6 & 88 & 12 & 6 & 86 & 14 \\
\hline
\end{tabular}

Graph.1, 2 Results (in \%) of the students' responses
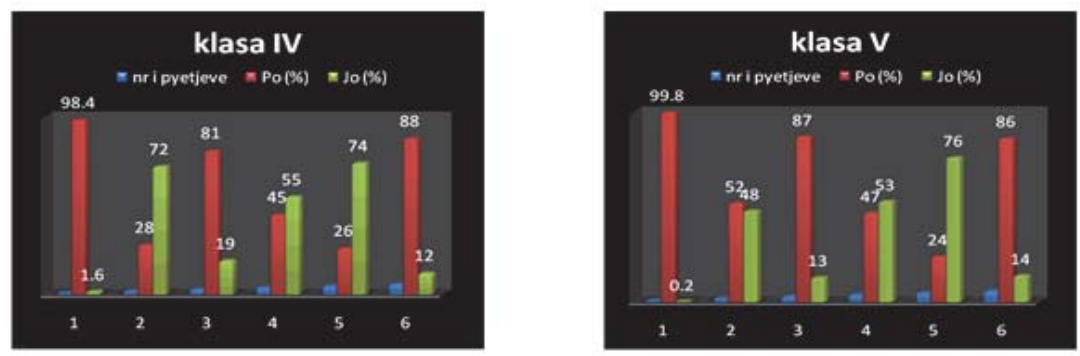
Graph. 3 Results (in \%) of the teachers' responses

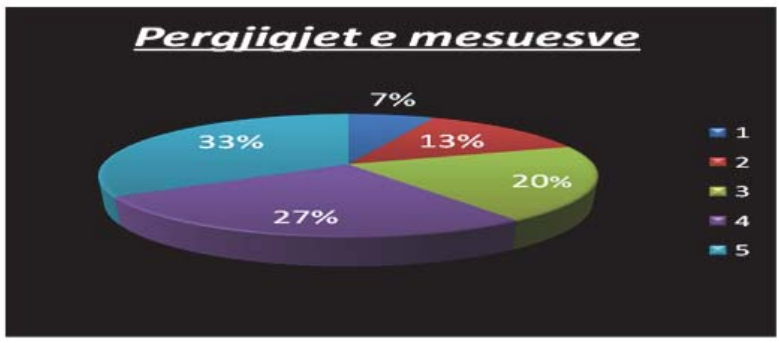

While analyzing these data in detail we can say that almost all students consider exerting physical activities and sports as important but, unfortunately, the physical education teacher do not respond to their interest and desire for these kinds of activities. They do not develop the physical education classes regularly, not to mention that some of them do not develop those classes at all, replacing them with classes from other subjects, within the teaching timeline process at school.

Although the majority of children prefer the physical education subject classes, ore to exert other motoric and sportive exercises, teachers do not support them and promote their desires by providing very little or no necessary knowledge and instructions about the physical education and sports.

Regarding the students' perceptions about the quality of the ambiences, to what extent they are suitable and safe, results show that the facilities to develop physical education and sports activities have been drastically limited. One of the factors effecting this situation is the economic, social and structural changes the urban centers have been through, bringing the total eradication of spaces where children could play by indiscriminate urban building processes. The ambiance or squares among blocks of flats or near schools which before made the usual ambiences for children to play carelessly, are unsafe at present and impossible for the children's traditional activities and games.

Also results show that the majority of students seek for more spaces to exert movements, both during the lessons' recesses and during the classes and they ask for the motoric activities to be integrated with the knowledge and wonts gained from other classes of the school curricula.

Moreover, the analyses of the results from the teachers' canvassing, it can be asserted that, unfortunately most of them do not develop the physical education and sports classes regularly and do not respond to the students' desires to be continuously moving, as well as to develop various sportive activities in and out of the school.

Almost everybody accepts and likes the idea of getting the physical education knowledge and wonts in the course of other subjects, but some of them are skeptical since they do not have the necessary theoretical and professional capacities to realize it.

They do not allow students to move during recesses and almost all of them lack knowledge about the concept "the school in move".

Regarding the reactions and suggestions linked with the promotion and development of the physical activities and sports in and out of school, the canvassing results showed that over $80 \%$ of the teachers need further and continuous qualifications to this aspect, regarding the infrastructure and the other necessary didactical means, the opening of the sportive classes and adding one more physical education class at schools.

\section{Conclusions}

The present-day deep social and economic changes have brought positive changes into improving both in the life of the individuals and in the life the society as a whole. However, in some other aspects these changes have brought negative effects in terms of ever more limitation of the motoric activities, conditioning a sedentary life and unhealthy nutriment, phenomena which have included even the younger generations at school.

While considering all the evaluations regarding the multidimensional education and development of the individuals in and advanced society, its worth to emphasize, once and again, the fact that primary school years, especially the 9years school years, are the years which are distinct even for the students' relations with motoric and sportive experiences. free time.

The child's world has been considered as being integrated in three great systems, suchlike: the family, school, and

In this integrated system each single element is necessary but the role of the school is determinative in terms of 
promoting the motoric and sportive activities, an intention which is fulfilled by means of the physical education subject and sports activities both in and out of this institution.

Moreover, through promoting the "School in move" model, we intend to widen this promotion even out of the school ambiances, by giving shape to a real physical culture, whose effects would undoubtedly be beneficial to the society as a whole.

\section{References}

Anderson, C.A., Dill, K.E.,(2002) "Videogames and Aggressive Thoughts, Feelings and Behavior in the Laboratory and in Life". Journal of Personality and Social Psychology.

Dashi, E. (2000) "Theiry of Human Motion". Pegi, Tiranë.

Dobbins, M.,et. al. (2009) "School-based physical activity programs for promoting physical activity and fitness in children and adolescents aged 6-18". Review: The Cochrane Library, Issue.

Hollmann, W., Lollgen, H. (2002) "Bedeutung der korperlichen Aktivitat fur kardiale und zerebrale funktionen" Deutsches Arzteblatt, Jg. 99. Heft 20, S. 1379-1381.

Kacurri, A. (2010) "Motor activities and the age". University text. Tiranë.

Kacurri, A. (2011) "Motion and Education". Pegi, Tiranë.

Kosanke, N., Warner, N. (1990) "Creative Play Areas". Nashville : School-Age Notes

Kubesch, S. (2004) "Das bewegte Gehirn-an der Schnittstelle von Sport und Neurowissenschaft". SpW 34 (2), S. 135-144.

Shepard, R. J. (1997) "Curricular Physical Activity and Academic Performance". Pediatric Exercise Science 9 (2), 113-126.

Viner, R. M., Cole, T. J., (2005) "Television viewing in early childhood predicts adult body mass index". J. Pediatr. 147(4), 429-435

Worpole, K. (2003) "No particular Place to Go". Groundwork Trust.

Zahner, L., et al. (2004) "Infanzia attiva-vita sana". Pacchetto didattico, UFSPO, Macolin. 